\title{
Comparative Study on the Antioxidative Properties of Some Natural Polymers Degraded by $\gamma$-rays
}

\section{N. M. El-Sawy ${ }^{\#}$, H. A. Abd El-Rehim, E. A. Hegazy, E. A.}

\author{
Soliman" and A. M. Elbarbary
}

Radiation Research of Polymer Chemistry Dept., National Centre for Radiation Research and Technology (NCRRT), P. O. Box; 29 Nasr City, Egypt. "E-mail: naeemelsawy@yahoo.co.uk and "Chemistry Dept., Faculty of Science, Ain Shams University, Cairo, Egypt.

\begin{abstract}
R ADIATION induced degradation of chitosan, Na-alginate and carrageenan was carried out to prepare oligosaccharides with different molecular wt. Structural and average molecular wt changes of such oligosaccharides were determined by gel permeation chromatography (GPC), Fourier transform infra-red (FT-IR) and ultraviolet (UV-Vis.) spectroscopy. FT-IR and UV-Vis. studies revealed that during radiation degradation process, the main polysaccharide chain structure was almost remained. Comparative study on the antioxidative properties of chitosan, Na-alginate and carrageenan oligosaccharides of different molecular wt was investigated. Radical mediated lipid peroxidation inhibition, scavenging effect on 1,1-diphenyl-2picrylhydrazyl (DPPH) radicals, reducing power and the ferrous ion chelating activity assays were used to evaluate the antioxidant activity. The irradiation process enhances the antioxidant activity of such polysaccharides. The lower the molecular wt of oligosaccharides is the higher the antioxidant activity. The antioxidant activity of irradiated chitosan was higher than Na-alginate and carrageenan. At $30 \mathrm{kGy}$, the inhibition concentration $\left(\mathrm{IC}_{50}\right)$ on DPPH radicals was $0.154,0.359,0.438$ and $0.140 \mathrm{mg} / \mathrm{ml}$ for chitosan, Na-alginate carrageenan, and ascorbic acid, respectively.

Keywords: $\gamma$-rays, natural polymers, degradation, chitosan, oligosaccharides, antioxidant activity.
\end{abstract}

The demands on new polymeric materials are increasing rapidly with the development of biotechnological science. Chitosan, Na-alginate and carrageenan are biodegradable natural polymers. They have wide range of applications such as wound healing and food packaging etc. (Carlson et al., 2008). 
They received much attention as biomaterials for value-added products, especially in food industry (Ikeda 2003), as a growth promoter or protector for some plants in the agricultural applications (El-Sawy et al., 2010) and as antioxidant agents for food preservation (Shahidi et al., 1999).

Antioxidants are classified as compounds capable of delaying, retarding or preventing auto-oxidation processes caused by reactive oxygen and they act as oxygen scavengers, react with free radicals and chelate catalytic metals and thus retard oxidative deterioration (Kanat et al., 1998). In recent years, great interest in finding natural antioxidants from plant materials or from different sources has been drawn more and more attention for use in foods or medicinal materials to replace synthetic antioxidants such as butylated hydroxyanisole and butylated hydroxytoluene. A multitude of natural antioxidants have already been isolated from different kinds of plant materials (Ramarathnam et al., 1995). Also, seaweed is considered to be a rich source of antioxidants (Cahyana et al., 1992). In recent years, polysaccharides from different sources were reported to be useful candidates in the search for an effective, nontoxic substance and have been demonstrated to play an important role as free radical scavengers in vitro and antioxidants for the prevention of oxidative damage in living organisms (Zhang et al., 2004). In many of antioxidants applications, specific molecular wt of polysaccharides are required. Radiation processing of natural polymers is an area of current research for development of new applications. Irradiation of these polymers led to the reduction of molecular wt by scission of glycosidic linkage (Charlesby 1981). Controlling the degree of degradation, uniform molecular wt distribution, saving achieved in the chemicals (used in conventional methods) on a cost basis, and environmentally friendly process are the beneficial effects of using radiation technology in these industries.

In the present work, preparation of low molecular wt oligosaccharides from chitosan, Na-alginate and carrageenan using ionizing radiation was carried out to increase their antioxidant activities.

\section{Materials and Methods}

Chitosan, degree of deacetylation $85 \%$ of high molecular wt, Na-alginate, Iota-carrageenan commercial grade type II, DPPH and 3-(2-pyridyl)-5,6diphenyl-1,2,4-triazine-4',4"'-disulfonic acid sodium salt (Ferrozine) were purchased from Sigma-Aldrich, USA. EDTA, ferric chloride, ferrous chloride,

Egypt. J. Rad. Sci. Applic., Vol. 24, No. 1 (2011) 
Potassium ferricyanide and Trichloroacetic acid were supplied from BDH, India. Other reagents and solvents were of analytical grade. The number average molecular wt of the degraded polymers were determined by GPC, 1100 Agilent instrument, USA and using a calibration curve using polyethylene oxide standards. UV-Vis spectrophotometer was carried by using Jasco V-560, Japan. FT-IR spectrophotometer was carried out in the form of $\mathrm{KBr}$ pellets by using JASCO FT-IR 6300, Japan.

Evaluation of antioxidant activity of unirradiated and irradiated natural polymers was investigated using different methods such as measurement of scavenging activity on DPPH radicals (Yamaguchi et al., 1998), the reducing power (Yen and Duh 1993) and the chelating effect on ferrous ion (Dinis et al., 1994). Chitosan (in $1 \%$ acetic acid) or Na-alginate or carrageenan solutions with different concentrations $(\mathrm{mg} / \mathrm{ml})$ were irradiated by ${ }^{60} \mathrm{Co} \gamma$-rays at different doses of 10,20 and $30 \mathrm{kGy}$ at dose rate of $3.52 \mathrm{kGy} / \mathrm{h}$ at the time of experiments. The irradiation facility was constructed by the NCRRT, Nasr City, Cairo, Egypt.

\section{Results and Discussion}

The changes in the number average molecular wt of chitosan, Na-alginate and carrageenan in aqueous solution using GPC after treating with gamma irradiation at different doses were shown in Fig. 1. There is a rapid decrease in the number average molecular wt of chitosan, Na-alginate and i-carrageenan. As the irradiation dose increases, the number average molecular wt of polysaccharides decrease. The number average molecular wt of chitosan, Na-alginate and carrageenan solution subjected to $10 \mathrm{kGy}$, decreased from $1.9 \times 10^{6}, 2.4 \times 10^{6}$ and $4.3 \times 10^{6}(\mathrm{Da})$ to $3.8 \times 10^{5}, 1.1 \times 10^{5}$ and $2.5 \times 10^{5}(\mathrm{Da})$, respectively. With increasing the irradiation dose to $30 \mathrm{kGy}$, the number average molecular wt reduced to $9.9 \times 10^{3}, 9.2 \times 10^{3}$ and $1.2 \times 10^{4}(\mathrm{Da})$, respectively. Polysaccharides are typical degradable materials under ionizing radiation which undergo degradation reactions through the $\beta-(1-4)$ glycosidic bond cleavage resulting in the reduction of its average molecular wt (Leonhardt et al., 1985). UV-Vis. spectra of unirradiated and irradiated chitosan, Na-alginate and carrageenan were illustrated in Fig. 2. For the irradiated chitosan, two absorption peaks at 275 and $315 \mathrm{~nm}$ were observed. The intensity of these peaks increased with increasing the irradiation dose. These two peaks may be due to 
the presence of unsaturated carbonyl and carboxyl groups. The obtained results are consistent with those reported by Ulanski and Rosiak (1992). For the irradiated Na-alginate and carrageenan, a new absorption band at $275 \mathrm{~nm}$ and the peak intensity increase with increasing the irradiation dose. It can be assigned to carbonyl group or hydroxyl group formed after the main chain scission of the polysaccharide (Nagasawa et al., 2000).

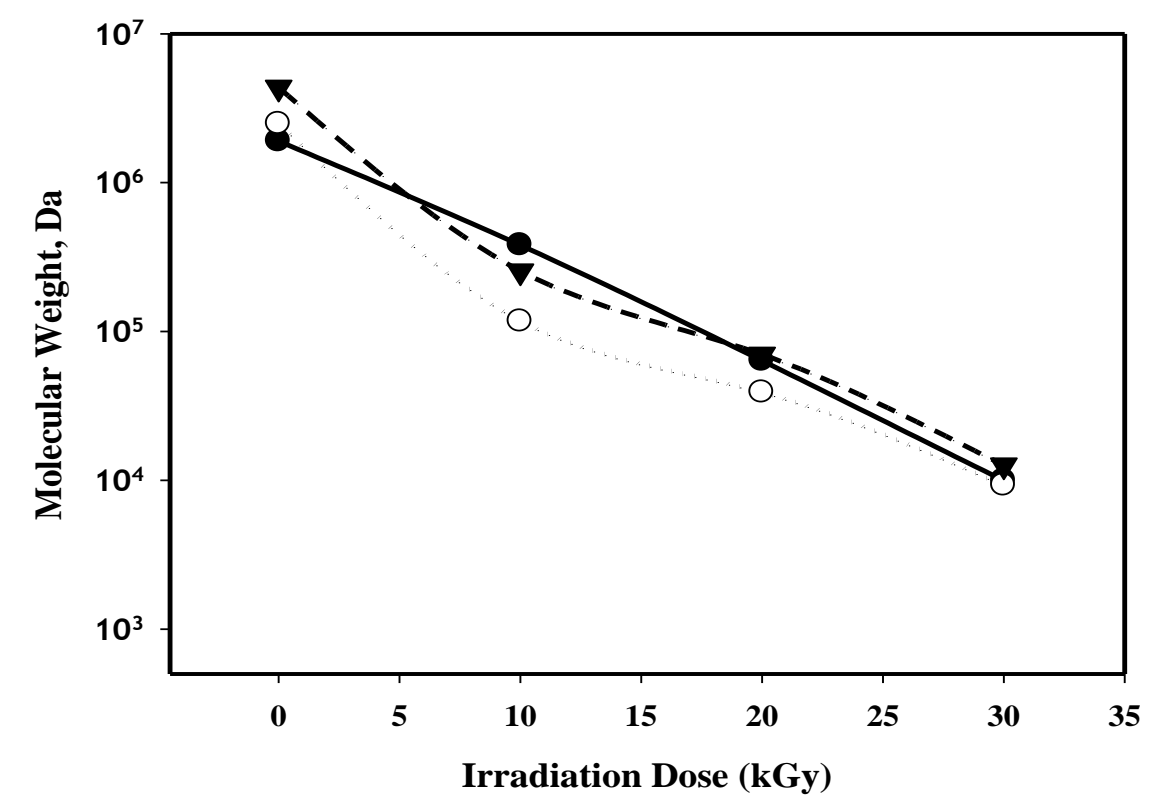

Fig. 1. The average molecular weights of $(\bullet)$ chitosan, $(\circ)$ Na-alginate and carrageenan in aqueous solution after $\gamma$-irradiation at different doses.

FT-IR spectra of unirradiated and irradiated chitosan, Na-alginate and carrageenan were shown in Fig. 3. FT-IR spectrum of chitosan (Fig. 3. A, curve a) shows distinctive absorption bands appeared at 3440, 1638, 1598, 1387, 1156 and $1097 \mathrm{~cm}^{-1}$ corresponds to $-\mathrm{OH}$ and $-\mathrm{NH}_{2}$ groups, stretching $\mathrm{C}=\mathrm{O}$ of amide group, $\mathrm{N}-\mathrm{H}$ bend, $\mathrm{NH}$ of amide, asymmetric bridge-O-stretch and skeletal vibration involving the $\mathrm{C}-\mathrm{O}$ stretch, respectively are characteristic of saccharine structure. For the irradiated chitosan (Fig. 3. A curves b, c \& d), it was observed that as the irradiation dose increases, the intensity of the absorption peak at $1602 \mathrm{~cm}^{-1}$ assigned to the $\mathrm{N}-\mathrm{H}$ bend vibration of $-\mathrm{NH}_{2}$ increases and shift to low wavenumber. This may be due to the decreasing of inter- or intra- molecular hydrogen bonding between the $-\mathrm{OH}$ and $-\mathrm{NH}_{2}$ groups.

Egypt. J. Rad. Sci. Applic., Vol. 24, No. 1 (2011) 
Additionally, another characteristic peak at $1638 \mathrm{~cm}^{-1}$, which could be disturbed by carbonyl groups of chitosan, was gradually shifted to $1645 \mathrm{~cm}^{-1}$, while its intensity increased with an increase in the $\gamma$-ray irradiation dose. Also, the intensity of the peak at $1385 \mathrm{~cm}^{-1}$ assigned to $\mathrm{C}-\mathrm{O}$ stretch vibration increased and moved toward the higher wavenumber as the irradiation dose increases. The vibrational band at $1100 \mathrm{~cm}^{-1}$ that corresponds to the ether bond in the pyranose ring has no significant change, which indicates that, the stability of the $\beta$ glycosidic bonds in the molecular chains of chitosan.

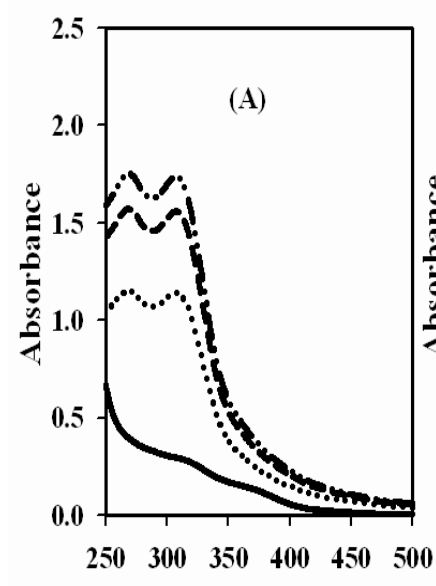

Wavelength (nm)

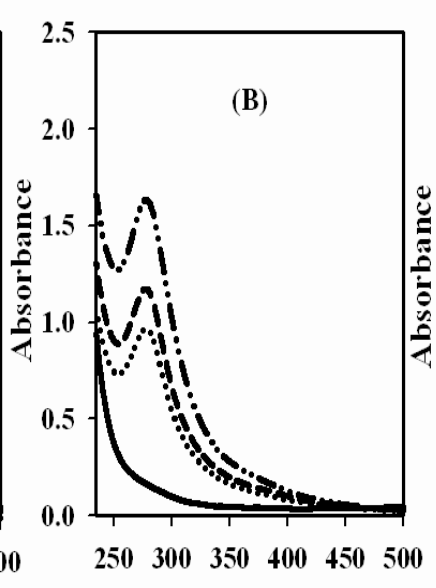

Wavelenghth (nm)

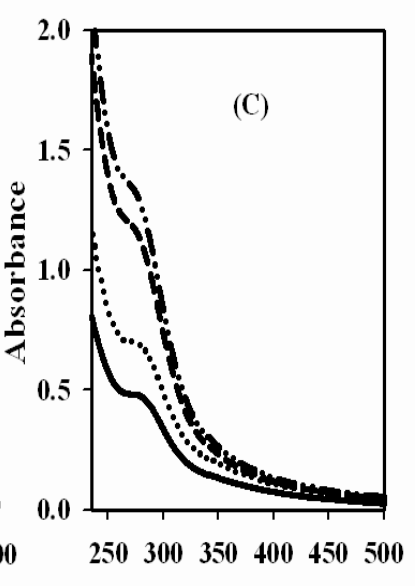

Wavelenghth (nm)

Fig. 2. UV-Vis spectra of (A) chitosan, (B) Na-alginate and (C) carrageenan, (一) unirradiated polysaccharide and irradiated polysaccharide at $10 \mathrm{kGy}$ (…), 20 kGy (---) and 30 kGy (-----).

In the spectrum of Na-alginate (3B, curve a), the peaks at 3390, 1620 and $1095-1035 \mathrm{~cm}^{-1}$ are attributed to hydroxyl, $\mathrm{C}-\mathrm{O}-\mathrm{O}$ and $\mathrm{C}-\mathrm{O}-\mathrm{C}$ groups, respectively (Sartori et al., 1997). Peak at $1610 \mathrm{~cm}^{-1}$ for $-\mathrm{COONa}$ of $\mathrm{Na}$ alginate was taken as the reference peaks due to the fact that carboxyl groups do not change after degradation. The spectrum of degraded Na-alginate (Fig. 3. B, curves b, c \& d) exhibited most of the characteristic absorption peaks of native alginate. The scission of glycosidic bonds leads to the formation of hydroxyl group, which is manifested as an increase in the ratio of hydroxyl group peak at $3425 \mathrm{~cm}^{-1}$. For unirradiated carrageenan spectrum (Fig. 3. C, curve a), the broad band between $855-805 \mathrm{~cm}^{-1}$ indicated to the sulphate groups that attached at the C-4 position of galactose.

Egypt. J. Rad. Sci. Applic., Vol. 24, No. 1 (2011) 
The band at $934 \mathrm{~cm}^{-1}$ was attributed to the presence of 3,6anhydrogalactose. The vibrational band at $1075 \mathrm{~cm}^{-1}$ corresponds to the ether bond in the pyranose ring. The peak at $1262 \mathrm{~cm}^{-1}$ was attributed to the asymmetric stretching of $\mathrm{S}=\mathrm{O}$. The absorption bands at 2941 and $3460 \mathrm{~cm}^{-1}$ due to $\mathrm{C}-\mathrm{H}$ stretch groups and hydroxyl $(\mathrm{OH})$ groups, respectively.
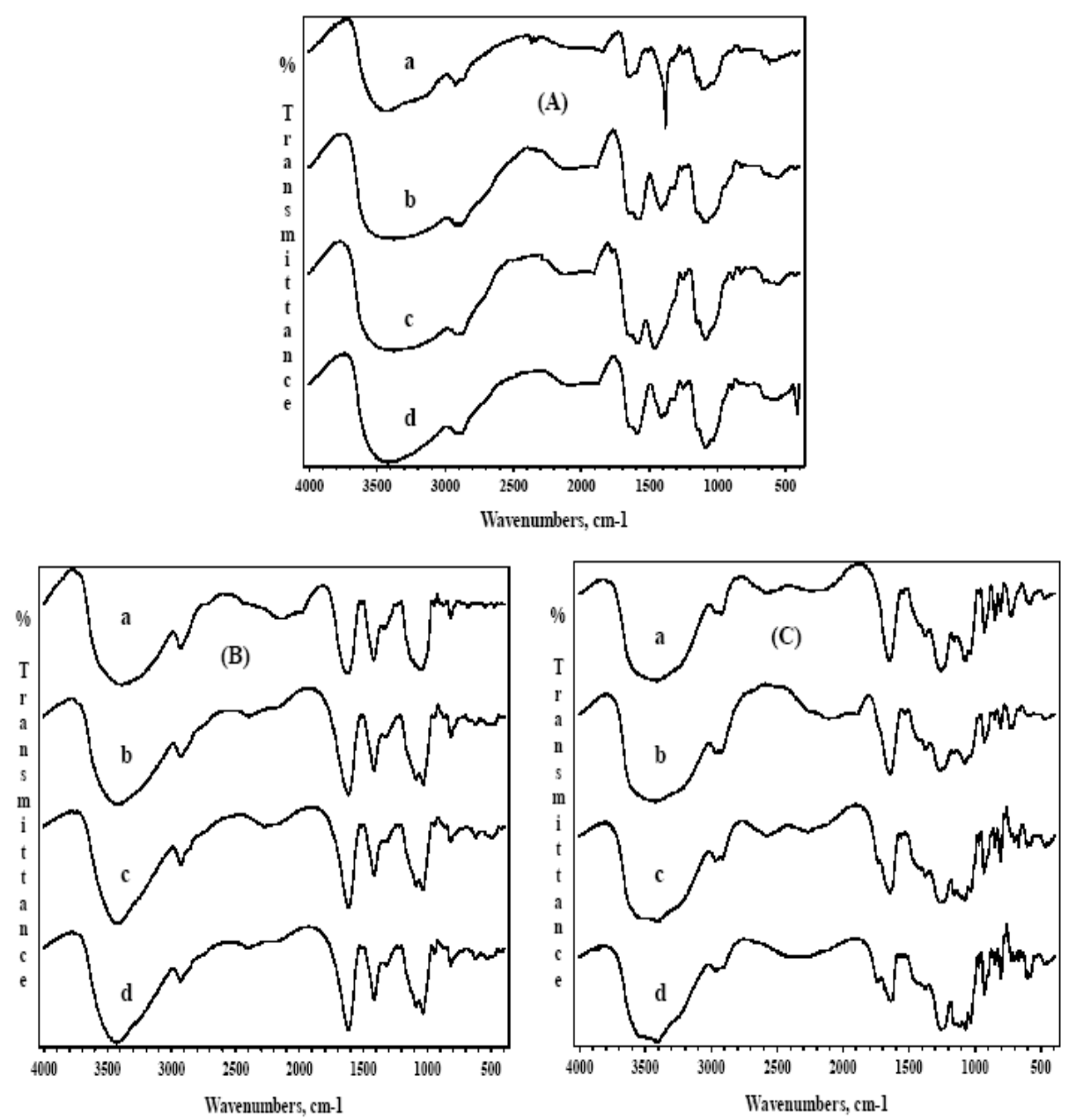

Fig. 3. FT-IR spectra of (A) chitosan, (B) Na-alginate and (C) carrageenan, (a) unirradiated polysaccharide and irradiated polysaccharide at (b) $10 \mathrm{kGy}$, (c) $20 \mathrm{kGy}$ and (d) $30 \mathrm{kGy}$.

The spectrum of irradiated carrageenan (Fig. 3. curves b, c \& d) exhibits most of the characteristic absorption peaks of unirradiated carrageenan but there Egypt. J. Rad. Sci. Applic., Vol. 24, No. 1 (2011) 
is a new band appeared at $1732 \mathrm{~cm}^{-1}$ due to glycoside bonds cleavage and formation of $-\mathrm{C}=\mathrm{O}$ groups.

From the data obtained by UV-Vis. and FT-IR studies, the proposed mechanism of degradation of chitosan, Na-alginate and carrageenan irradiated in liquid state could be illustrated in Schema. 1.

DPPH is one of the compounds that possessed a proton free radical with a characteristic absorption, which decreases significantly on exposure to proton radical scavengers. Further, it is well accepted that the DPPH free radical scavenging by antioxidants is due to their hydrogen-donating ability (Chen and Ho, 1995). DPPH scavenging effect (\%) of chitosan, Na-alginate and carrageenan with different concentrations and irradiation doses were measured and the results were depicted in Fig. 4. In general DPPH radical scavenging effect $(\%)$ of chitosan, Na-alginate and carrageenan increased with increasing the polysaccharide concentration to a certain extent about $1 \mathrm{mg} / \mathrm{ml}$ and then it levelled off even with further increase in the concentration. Also, an increase in the DPPH radical scavenging effect (\%) was observed by increasing the irradiation dose of polysaccharides.
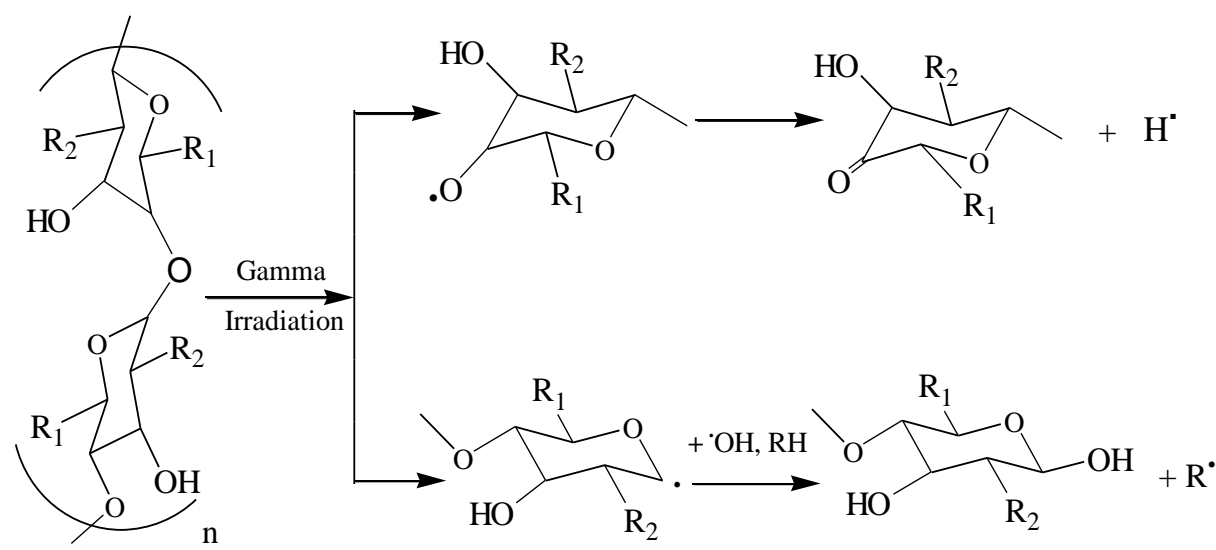

Polysaccharide

$$
\begin{array}{llll}
\text { Chitosan, } & \mathrm{R}_{1}=\mathrm{CH}_{2} \mathrm{OH} & \text { and } & \mathrm{R}_{2}=\mathrm{NH}_{2} \\
\text { Na-alginate, } & \mathrm{R}_{1}=\mathrm{COONa} & \text { and } & \mathrm{R}_{2}=\mathrm{OH} \\
\text { Carageenan, } & \mathrm{R}_{1}=\mathrm{CH}_{2} \mathrm{OH} & \text { and } & \mathrm{R}_{2}=\mathrm{OSO}_{3} \mathrm{Na}
\end{array}
$$

Schema. 1. Proposed mechanism of radiation induced degradation of chitosan, Naalginate and carrageenan.

Egypt. J. Rad. Sci. Applic., Vol. 24, No. 1 (2011) 
The results revealed that the DPPH radical scavenging effect (\%) of investigated polysaccharides followed the order chitosan > Na-alginate > carrageenan. The DPPH scavenging effect (\%) for the unirradiated chitosan, Na-alginate and carrageenan at a concentration of $0.5 \mathrm{mg} / \mathrm{ml}$ was $5,3.2$ and 3.1 (\%), respectively. Meanwhile, using 30kGy irradiation dose, the DPPH scavenging effect $(\%)$ became $60.2,52.7$ and $51.1(\%)$, respectively. The DPPH scavenging effect $(\%)$ of chitosan irradiated at $30 \mathrm{kGy}$ is nearly the same as that of ascorbic acid which is $62.5(\%)$. $\mathrm{IC}_{50}$ of DPPH radical scavenging effect (\%) was determined to be $0.154,0.359$, and $0.438 \mathrm{mg} / \mathrm{ml}$ for chitosan, Na-alginate and carrageenan irradiated at $30 \mathrm{kGy}$, respectively as compared by that of ascorbic acid $0.140 \mathrm{mg} / \mathrm{ml}$. These results revealed that the irradiation of chitosan enhances its antioxidant activity.
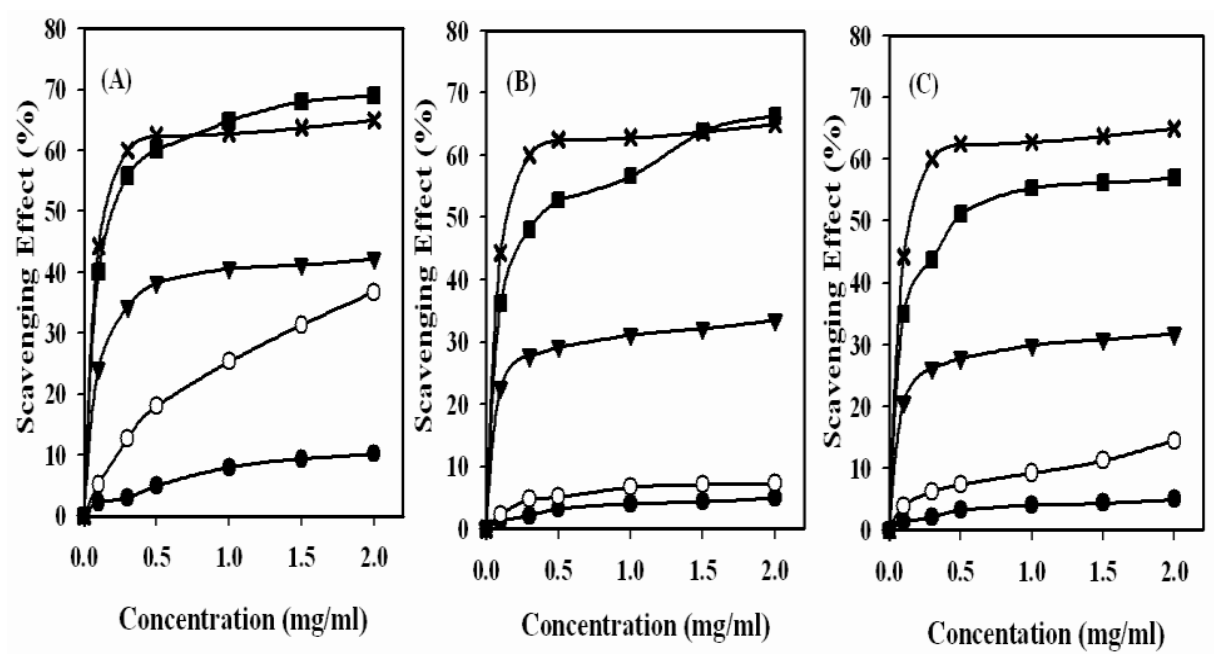

Fig. 4. Scavenging effect (\%) of (A) chitosan, (B) Na-alginate and (C) carrageenan; irradiated at different doses on DPPH radicals. (x) ascorbic acid as reference, $(\bullet)$ unirradiated polysaccharides and the irradiated polysaccharides at $(0)$ $10 \mathrm{kGy},(\nabla) 20 \mathrm{kGy}$ and (a) 30kGy.

The reducing capacity of a compound may serve as a significant indicator for its potential antioxidant activity. The reducing power of unirradiated and irradiated chitosan, Na-alginate and carrageenan at different doses as a function of concentration comparing with ascorbic acid (positive control) was shown in Fig. 5. Low molecular wt polysaccharides showed high reducing power, and the Egypt. J. Rad. Sci. Applic., Vol. 24, No. 1 (2011) 
reducing power increased with increasing the polysaccharides concentration. The reducing power of irradiated chitosan is much higher than that of $\mathrm{Na}$ alginate and carrageenan. At $2 \mathrm{mg} / \mathrm{ml}$ concentration, the reducing power of unirradiated chitosan, Na-alginate and carrageenan was $0.3319,0.3504$ and 0.3146 , respectively. Using $30 \mathrm{kGy}$ irradiation dose and $2 \mathrm{mg} / \mathrm{ml}$ polysaccharide concentration, the reducing power of chitosan, Na-alginate and carrageenan became $1.3574,1.2380$ and 0.9377 , respectively. Meanwhile, the reducing power of ascorbic acid was 1.48 . The reducing power properties are generally associated with the presence of reducing agent. The role of reducing agents is to exert antioxidant action by breaking the free radicals chain by donating a hydrogen atom (Gordon 1990).

The chelating effect (\%) of unirradiated and irradiated chitosan, Naalginate and carrageenan at different doses as a function of concentration using EDTA as positive control was shown in Fig. 6. Low molecular wt polysaccharides showed high chelating ability. The chelating ability increased with the increase of polysaccharides concentration.
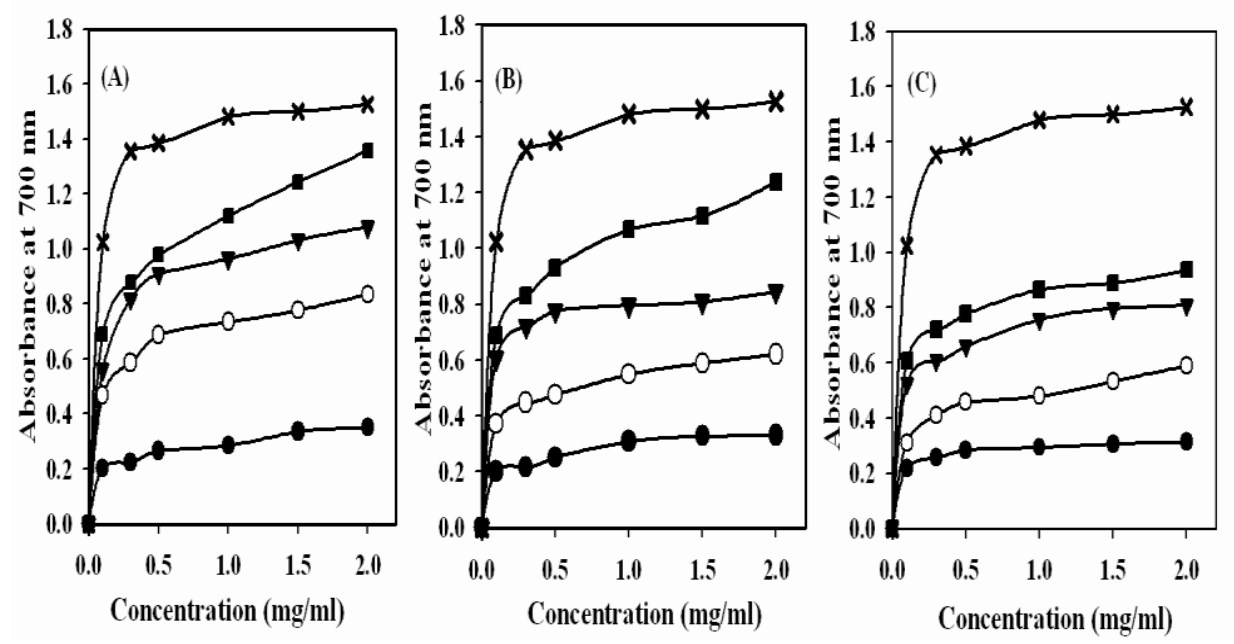

Fig. 5. Reducing power of (A) chitosan, (B) Na-alginate and (C) carrageenan; irradiated at different doses. (x) ascorbic acid as reference, $(\bullet)$ unirradiated polysaccharides and the irradiated polysaccharides at $(0)$ $10 \mathrm{kGy},(\nabla) 20 \mathrm{kGy}$ and (-) $30 \mathrm{kGy}$.

Egypt. J. Rad. Sci. Applic., Vol. 24, No. 1 (2011) 

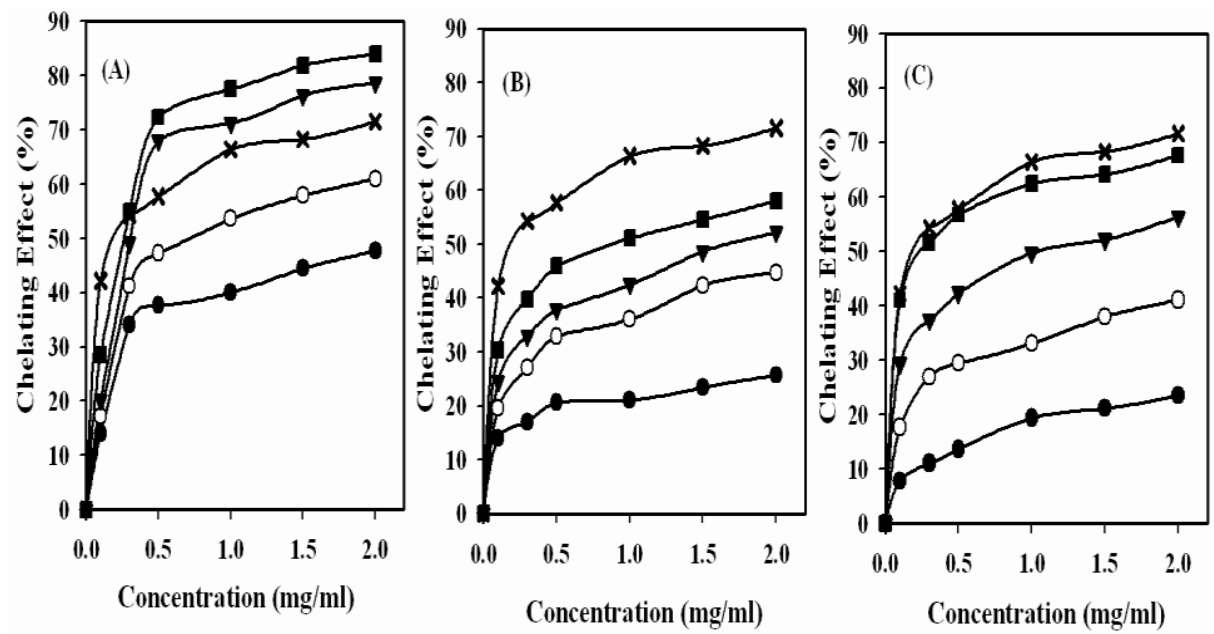

Fig. 6. Chelating effect (\%) of (A) chitosan, (B) Na-alginate and (C) carrageenan; irradiated at different doses. (x) EDTA as reference, $(\bullet)$ unirradiated polysaccharides and the irradiated polysaccharides at $(\circ) 10 \mathrm{kGy},(\nabla) 20 \mathrm{kGy}$ and (घ) 30kGy.

The results revealed that the irradiated chitosan had the highest chelating ability. The affinity of chitosan to chelate $\mathrm{Fe}^{2+}$ ion mainly comes from the presence of amino groups, which contain lone electron pairs that help to form chitosan- $\mathrm{Fe}^{2+}$ complexes (Guzman et al., 2003). At $1 \mathrm{mg} / \mathrm{ml}$ concentration, the chelating (\%) of unirradiated; chitosan, Na-alginate and carrageenan was 40 , 21.1 and $19.3(\%)$, respectively, in comparison with that of EDTA which gave $66.4(\%)$. Using 30kGy irradiation dose, the chelating (\%) of chitosan, Naalginate and carrageenan became 77.5, 51.1 and $62.4(\%)$, respectively. $\mathrm{IC}_{50}$ of the chelating effect (\%) was $0.2293,0.8023$ and 0.238 for chitosan irradiated at 20kGy, Na-alginate irradiated at 30kGy and carrageenan irradiated at 30kGy, respectively. The chelating effect (\%) of 30kGy irradiated chitosan was higher than that of Na-alginate and/ or carrageenan.

\section{Conclusions}

A rapid decrease in the number average molecular wt of chitosan, Naalginate and carrageenan was obtained during the radiation induced degradation process. FT-IR, UV-Vis. spectroscopy revealed that the main polysaccharide chain structure was almost remained after degradation. The increase in the irradiation dose of $\gamma$-ray treatment and concentration of polysaccharides

Egypt. J. Rad. Sci. Applic., Vol. 24, No. 1 (2011) 
increased the antioxidant activities. The results showed that the chitosan oligosaccharide possessed the highest scavenging effect on DPPH radicals rather than Na-alginate and carrageenan oligosaccharides. Also, the 30kGy irradiated chitosan had nearly the same antioxidant activity of ascorbic acid at the same concentration and can be used as a source of natural antioxidant for food shelf life extension.

\section{References}

Cahyana, A. H., Shuto, Y. and Kinoshita, Y. (1992) Pyropheophytin as an antioxidative substance from the marine alga, Arame (Eicenia bicyclis). Biosci. Biotechn. Agrochem., 56, 1533.

Carlson, R. P., Taffs, R., Davison, W. M, and Stewart, P. S. (2008) Anti-biofilm properties of chitosan-coated surfaces. J. Biomat. Sci. Polym., 19, 1035.

Charlesby, A. (1981) Crosslinking and degradation of polymers. Radiat. Phys. Chem., $18,59$.

Chen, C. W, and Ho, C. T. (1995) Antioxidant properties of polphenols extracted from green and black teas. J. Food Lipids, 2, 35.

Dinis, T. C. P., Madeira, V. M. C and Almeida, L. M. (1994) Action of Phenolic Derivatives (Acetaminophen, Salicylate, and 5-Aminosalicylate) as Inhibitors of Membrane Lipid Peroxidation and as Peroxyl Radical Scavengers. Arch. Biochem. Biophys., 315, 169.

El-Sawy, N. M., Abd El-Rehim, H. A., Elbarbary, A. M. and Hegazy, E. A. (2010) Radiation-induced degradation of chitosan for possible use as a growth promoter in agricultural purposes. Carbohyd. Polym., 79, 555.

Gordon, M. H. (1990) In Food Antioxidants; Hudson, B.J.F., Edn. Elsevier Applied Science, London, pp. 1-18.

Guzman, J., Saucedo, I., Revilla, J., Navarro, R. and Guibal, E. (2003) Copper sorption by chitosan in the presence of citrate ions: influence of metal speciation on sorption mechanism and uptake capacities. Int. J. Biolog. Macromol., 33, 57.

Ikeda, S. (2003) Structure and physical properties of polysaccharides for the food industry: carrageenans. Foods Food Ingred. J., 208, 801.

Kanat, S. R., Pau,I P., D'Souza, S. F. and Thomas, P. (1998) Lipid peroxidation in chicken meat during chilled storage as affected by antioxidants combined with low dose gamma irradiation. J. Food Sci., 63, 198.

Leonhardt, J., Arnold, G., Baer, M., Langguth, H., Gey, M. and Hgbert, S. (1985) Radiation degradation of cellulose. Radiat. Phys. Chem., 25, 899.

Nagasawa, N., Mitomo, H., Yoshii, F. and Kume, T. (2000) Radiation-induced degradation of sodium alginate. Polym. Deg. Stab., 69, 279.

Egypt. J. Rad. Sci. Applic., Vol. 24, No. 1 (2011) 
Ramarathnam, N., Osawa, T., Ochi, H. and Kawakishi, S. (1995) The contribution of plant food antioxidants to human health. Trends Food Sci. Techn., 6, 75.

Sartori, C., Finch, S. D. and Ralph, B. (1997) Determination of the cation content of alginate thin films by FTIR spectroscopy. Polym., 38, 43.

Shahidi, F., Arachchi, J. K. V. and Jeon, Y. J. (1999) Food applications of chitin and chitosans. Trends in Food Sci. Tech., 10, 37.

Ulanski, P. and Rosiak, J. M. (1992) Preliminary studies on radiation-induced changes in chitosan. Radiat. Phys. Chem. Int., 39, 53.

Yamaguchi, T., Takamura, H., Matoba, T. and Terao, J. (1998) HPLC Method for Evaluation of the Free Radical-scavenging Activity of Foods by Using 1,1Diphenyl-2-picrylhydrazyl. Biosci. Biotechn. Biochem., 62, 1201.

Yen, G. C. and Duh, P. D. (1993) Antioxidative properties of methanolic extracts from peanut hulls. J. Am. Oil Chem. Soc., 70, 383.

Zhang, Q. B., Li. N., Liu, X. G., Zhao, Z. Q., Li, Z. E. and Xu, Z. H. (2004) The structure of a sulfated galactan from Porphyra haitanensis and its in vivo antioxidant activity. Carbohyd. Res., 339, 105.

(Received: 13/11/2011;

accepted: 05/12/2011)

Egypt. J. Rad. Sci. Applic., Vol. 24, No. 1 (2011) 


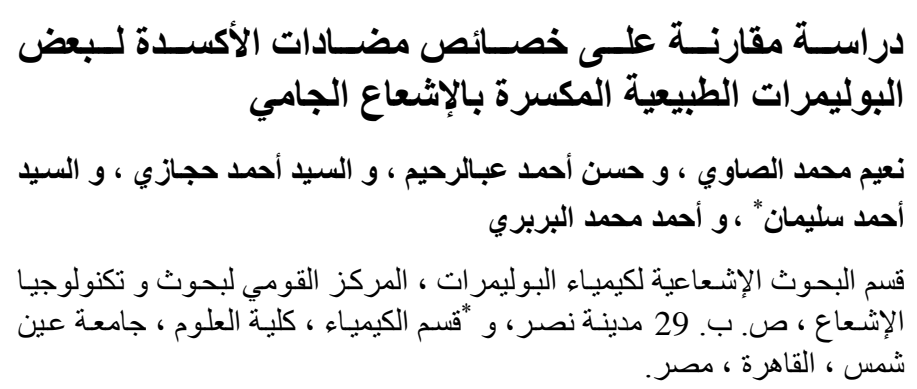

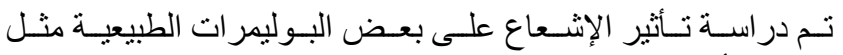

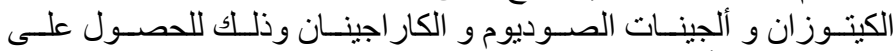

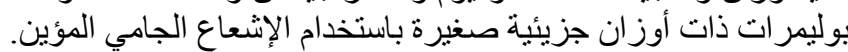

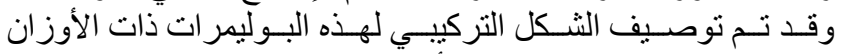

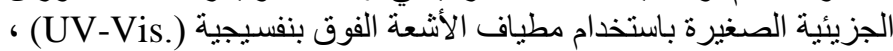

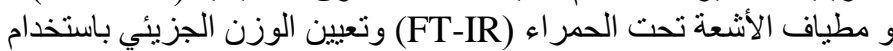
الجيل الكروماتوجر افي المنفذ (GPC).

أوضحت النتائج أن الوزن الجزئن (GPئي ينقص بزيـادة الجر عـة الإنشعاعية

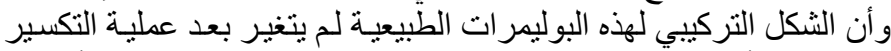

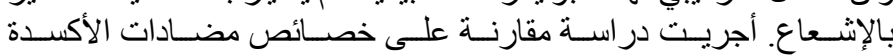

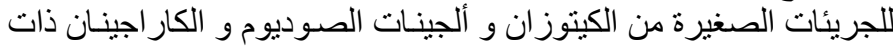

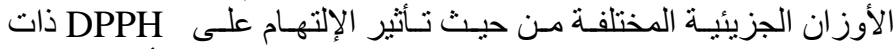

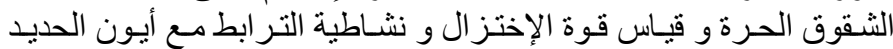

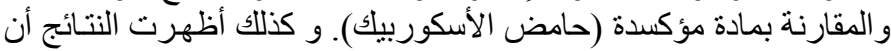

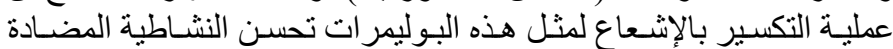

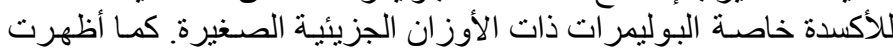

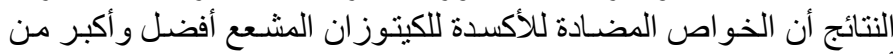

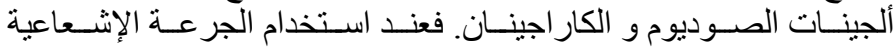

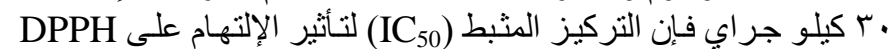

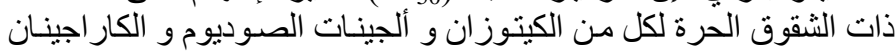

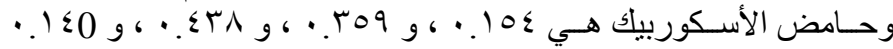

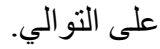

Egypt. J. Rad. Sci. Applic., Vol. 24, No. 1 (2011) 